\title{
Networking frameworks: a method for analyzing the complexities of classroom cultures focusing on justifying
}

\author{
Eva Thanheiser ${ }^{1}$ (D) $\cdot$ Kathleen Melhuish ${ }^{2} \cdot$ Amanda Sugimoto $^{1} \cdot$ Brenda Rosencrans $^{1}$. \\ Ruth Heaton ${ }^{3}$
}

Accepted: 10 January 2021/ Published online: 2 April 2021

(C) The Author(s) 2021

\begin{abstract}
In this paper, we network five frameworks (cognitive demand, lesson cohesion, cognitive engagement, collective argumentation, and student contribution) for an analytic approach that allows us to present a more holistic picture of classrooms which engage students in justifying. We network these frameworks around the edges of the instructional triangle as a means to coordinate them to illustrate the observable relationships among teacher, students(s), and content. We illustrate the potential of integrating these frameworks via analysis of two lessons that, while sharing surface level similarities, are profoundly different when considering the complexities of a classroom focused on justifying. We found that this integrated comparison across all dimensions (rather than focusing on just one or two) was a useful way to compare lessons with respect to a classroom culture that is characterized by students engaging in justifying.
\end{abstract}

Keywords Networking frameworks · Justifying · Elementary classroom · Student engagement · Instructional triangle

\section{Introduction}

Justifying is highlighted as a beneficial student activity in mathematics policy documents in many countries (for example, National Governors Association Center for Best Practices \& Council of Chief State School Officers, 2010 (USA); National Council of Teachers of Mathematics, 2000 (USA); Department for Education, 2014 (UK); Australian Curriculum,

Eva Thanheiser

evat@pdx.edu

1 Portland State University, Portland, OR, USA

2 Texas State University, San Marcos, TX, USA

3 Teachers Development Group, West Linn, OR, USA 
Assessment and Reporting Authority (ACARA), 2017 (Australia); Bildungspläne BadenWürttemberg (Germany)). Broadly speaking, justifying can be conceived as providing a mathematical "why" for procedures and properties that rely on leveraging mathematical meaning and structure rather than appealing to a rule, an authority, or examples (Brodie, 2010; De Villiers, 1990; Mata-Pereira \& da Ponte, 2017; Reid, 2002; Staples, Bartlo, \& Thanheiser, 2012; Stylianides, 2007). For younger students, justifying why a line of reasoning makes sense mathematically helps students move from reasoning empirically or procedurally to reasoning about mathematical structure and generalized quantities. Furthermore, justifying supports students in learning to construct deductive arguments (Brodie, 2010; Ellis, 2007; Jeannotte \& Kieran, 2017; Reid, 2002). Classrooms where students regularly engage in such activity have been linked with learning gains and more equitable outcomes (Boaler \& Staples, 2008).

The mathematics education literature points to several important characteristics of mathematics classrooms focused on engaging students in justifying. In these classrooms, student voices are heard, and student thinking is leveraged as the means to move instruction forward (e.g., Anthony, Kaur, Ohtani, \& Clarke, 2013; Ball, 1993; Jacobs \& Spangler, 2017; Jeannotte \& Kieran, 2017; MataPereira \& da Ponte, 2017; Munter, 2014; Nasir \& Cobb, 2006; Reid, 2002; Schoenfeld, 2011; Turner, Dominguez, Maldonado, \& Empson, 2013; Walshaw \& Anthony, 2008). In support of this aim, standards set by national and state organizations call for student-centered and collaborative classrooms (i.e., Australian Curriculum, 2017; Baden-Württemberg, 2016; National Council of Teachers of Mathematics, 2018; National Governors Association Center for Best Practices \& Council of Chief State School Officers, 2010) that provide opportunities for students to reason about mathematics and (co-) construct an understanding of mathematics as a part of a learning community (Boaler \& Staples, 2008; Lampert, 2001; National Research Council, 2001; Staples, 2007). To this end, researchers have sought to document evidence of the types of rich mathematical engagement that is valued in K-16 classrooms. In such classrooms, students are positioned as capable mathematics learners through the teachers' support of equitable and meaningful participation in classroom discourse (Turner et al., 2013).

Two aspects of instruction have been identified as essential to engage students in justifying, namely, the task posed and the way the teacher leads the discussion (da Ponte \& Quaresma, 2016). The tasks posed in the classroom need to allow for multiple entry points for all students as well as the opportunity to justify and/or generalize (Brodie, 2010; da Ponte \& Quaresma, 2016; Stein \& Smith, 1998), thus, be of high cognitive demand (Stein \& Smith, 1998). In addition to the selection of tasks, teacher support for developing students' justifying, reasoning, and communication skills is essential (Ball \& Bass, 2003; Mata-Pereira \& da Ponte, 2017). Whole class discussions have been identified as having a strong potential to foster student learning (Mata-Pereira \& da Ponte, 2017). The teacher's role in the whole class discussion enables students to articulate their contributions (Mata-Pereira \& da Ponte, 2017), engage in discussions as a means to understand, evaluate each other's complete and partial ideas (Brodie, 2010; Sowder \& Harel, 1998), and explore disagreements (Wood, 1999), thus creating space for students to assess the validity of each other's contributions (Ball \& Bass, 2003; Stein, Engle, Smith, \& Hughes, 2008). Importantly, classrooms characterized by high cognitive demand tasks, exploration of multiple solutions, and teachers that create a supportive and equitable community saw increases in student achievement and a reduction in achievement gaps between students of different ethnic and cultural groups (Boaler \& Staples, 2008).

Yet, learning to enact classroom practices that engender students in justifying is complex, and requires the learning of intentional and specific teacher moves and persistence in 
practicing these moves over time (Boaler \& Staples, 2008; Franke, Kazemi, \& Battey, 2007; Staples, 2007). This kind of teaching requires teachers to possess extensive knowledge of students' learning progressions, an understanding of how to make productive problem solving visible, and how to teach students to reason mathematically while simultaneously teaching students the classroom norms of sharing thinking, error analysis, and making sense of other students' ideas (Boaler \& Staples, 2008; Lampert et al., 2013; Staples, 2007). In order to create opportunity for justifying, and students' active engagement in justifying, a teacher's work includes identifying and uncovering students' mathematical thinking, making the students' sense making process visible to other students, and promoting a norm where such processes are both valued and critiqued by students.

Researchers have made sense of this complex work through various frameworks and observation tools. Some of these frameworks focus on eliciting student thinking, supporting understanding, and extending student thinking (e.g., Cengiz, Kline, \& Grant, 2011; Conner, Singletary, Smith, Wagner, \& Francisco, 2014) with some frameworks distinguishing between a focus on mathematics versus a focus on managing learning (da Ponte \& Quaresma, 2016). Observation tools focused on high-quality mathematics classrooms often attend mainly to the teacher (Praetorius \& Charalambous, 2018). Of the 12 observation tools included in ZDM's special issue Studying instructional quality in mathematics through different lenses: In search of common ground (2018), Praetorius and Charalambous (2018) found that 11 had the teacher as their main focus, while only one (Schoenfeld, 2018) had the student as its main focus. Of the 11 tools attending to teachers and teaching practices, only 4 also considered students as a secondary focus, while none of the tools considered the teacher, the students, and the tasks.

In our work, we use our observations and analyses of two lessons to network (BiknerAhsbahs \& Prediger, 2010; Tabach, Rasmussen, Dreyfus, \& Apkarian, 2020) several existing frameworks to make sense of the complex phenomenon of high-quality mathematics classrooms focused on engaging students in justifying. Bikner-Ahsbahs and Prediger defined networking as "research practices that aim at creating a dialogue and establishing relationships between parts of theoretical approaches while respecting the identity of the different approaches" (Bikner-Ahsbahs \& Prediger, 2014, p. 118). We coordinate and combine (BiknerAhsbahs \& Prediger, 2010) existing frameworks to help us in "better capturing instructional complexity" (Charalambous \& Praetorius, 2018, p. 359; Tabach et al., 2020), characteristic of high-quality mathematics classrooms, with the instructional goal of engaging students in justifying. Coordinating and combining have as their goal a "networked understanding of an empirical phenomenon or a piece of data" (Bikner-Ahsbahs \& Prediger, 2010, p. 495). In addition, such coordination of existing frameworks can lead to the development of a framework that goes beyond understanding particular data to contributing a new integrated framework (Prediger, Bikner-Ahsbahs, \& Arzarello, 2008)

We draw on pertinent analytic frameworks "since mathematics learning and teaching is a multi-faceted phenomenon which cannot be described, understood or explained by one monolithic theory alone, a variety of theories is necessary to do justice to the complexity of the field" (Bikner-Ahsbahs \& Prediger, 2006, p. 484). In selecting analytic frameworks, we focus on the two aspects named above (1) the task and (2) the teacher's role in leading the discussion. We expand those to include a third consideration, (3) students' engagement, since ultimately the goal is to engage students in justifying.

In this article, our goal is to coordinate existing frameworks to allow us to see a picture of the mathematics classroom characterized by teaching and learning practices intended to engage students in justifying that might not be visible with just one of the frameworks (Bikner- 
Ahsbahs \& Prediger, 2006; Charalambous \& Praetorius, 2018). Thus, we consider the variety of frameworks used as a "resource for grasping complexity that is scientifically necessary" (Bikner-Ahsbahs \& Prediger, 2010, p. 489) to understand the features and relationships among features within high-quality instruction. In particular, we investigated the following: How can we operationalize and coordinate various frameworks in order to identify and document elements of rich mathematics teaching that engage K-5 students in mathematical reasoning, including justifying?

\section{Motivation for our theoretical exploration}

The motivation for this work stems from the observation of two fourth-grade math lessons in the USA. The lessons shared many components: the nature of the content, students contributed frequently, and students had time to work on the mathematics. Yet, as researchers, we observed clear differences between the two lessons. There was a notable difference between classrooms in the quality and depth of the interactions in the classroom and the level of engagement with the content. This was particularly evident in terms of student contributions where justification appeared to be a strong aspect in one but not in the other lesson. We sought to make sense of various differences with regard to classroom culture characterized by students engaging in justifying in order to operationalize components of ambitious mathematics instruction.

We examined the classroom discussion by focusing on (1) the task, (2) the teacher's role in leading the mathematical discussions, and (3) students' engagement. We reviewed the literature for frameworks that would help us analyze the two lessons with respect to classroom culture characterized by students engaging in justifying.

The National Research Council (National Research Council, 2001) defines justification as the act of providing sufficient reason for mathematical ideas or strategies. An important distinction between mathematical proof and mathematical justification is that justifications do not have to be logically complete (Jaffe, 1997). We defined justifying as follows:

Justifying: Reason[ing] with meaning of ideas, definitions, math properties, established generalizations to (a) show why an idea/solution is true; (b) refute the validity of an idea; and (c) give mathematical defense of an idea that was challenged (Teachers Development Group, 2013, p. 41). [Note that justifying does not need to be correct or complete to be counted as such].

Justifying provides essential tools in classrooms where students can come to make sense of important mathematical structures, ideas, and strategies. As such, we were looking for frameworks that emphasized a focus on deeply engaging with mathematical content and supporting students in justifying as a means for students to be positioned as contributors to mathematics. We describe each of the frameworks below and then illustrate how we see the frameworks connecting to one another. When viewed simultaneously and as interconnected, these frameworks helped us identify and operationalize how the classroom cultures of students engaging in justifying varied across the two lessons.

We add to the literature by sharing a way to analyze elementary classrooms focused on students engaging in justifying by coordinating five frameworks as a whole (rather than focusing on any particular framework's various parts). These frameworks are lesson cohesion (Smith \& Stein, 1998; Stein \& Smith, 2011), cognitive demand (Smith \& Stein, 1998), 
collective argumentation (Conner et al., 2014), student contributions (Melhuish, Thanheiser, \& Fagan, 2019), and cognitive engagement activity (Chi \& Wylie, 2014). In this paper, we did not set out to examine why these differences occurred. Rather, we focused on how to examine and explain the differences.

\section{Theoretical assumptions}

Our work leverages a social cultural approach to make sense of the mathematics classroom. That is, we focus not on individual students' cognition but rather on the social interactions between people in the classroom, a social setting (Smith, 1998). Furthermore, we assume that within these interactions, knowledge is co-constructed by students with the support of the teacher (Cengiz et al., 2011). We also acknowledge that individual cognition and social interactions are closely related in that students communicate their personal understandings and develop individual understanding during social interaction (cf. Cobb \& Yackel, 1996; Sfard, 2012). By recognizing the reflexivity of the social and cognitive, we argue that frameworks which have been developed from a cognitive standpoint, but have been used to address outward activity (e.g., Chi \& Wylie, 2014; Smith \& Stein, 1998), can be leveraged to consider classroom structures. Such an argument echoes Sfard's (2012) argument for commognition - internal and interpersonal communication reflects the same mathematical discourse. However, unlike Sfard, we are not focusing on the nuances of mathematical discourse, but rather on the culture of the classroom from a more global view that addresses the ways that students, teacher, and mathematical tasks interact.

While a social cultural lens provides the general underpinnings of this approach, we focus specifically on components of a classroom culture in relation to the promotion of justifying. Broadly, a classroom culture reflects a pattern of interactions where "students and teachers, together with tasks and different elements in the classroom give rise to the particular recurrent interactions that comprise classroom cultures" (Lozano, 2017, p. 897). Thus, a classroom culture of justifying would include recurrent actions that reflect promotion of and student engagement in justifying. Justifying, and more broadly mathematical argumentation, can play an essential role in the process of co-constructing mathematical meaning (Brown \& Renshaw, 2000; Simon \& Blume, 1996) and promoting conceptual understanding (Staples et al., 2012) as students work to negotiate and make sense of mathematical structure.

\section{Methodology}

In this article, our goal was to analyze and understand what is happening within a lesson and across lessons with respect to the classroom culture that is characterized by students engaging in justifying. To do this, we analyze two lessons to illustrate the utility of using the coordination of five dimensions/frameworks, namely, (1) lesson cohesion, (2) cognitive demand of tasks, (3) collective argumentation, (4) student contribution types, and (5) students' cognitive engagement activity.

\subsection{Data sources}

For this study, data includes two videotaped mathematics lessons. For both lessons, we had video of the lessons, detailed field notes, and transcripts. For this analysis, we primarily 
Table 1 Lesson descriptions including sample exchanges

Lesson 1
Students sit at tables in groups of four to six students ( 2 students at a table, two to three tables pushed together), all facing the front of the room. Students each have an opened notebook on the table in front of them. The walls are full of posters and notes. There is a projector at the front of the room projecting on a screen (in front of a white board).

Summary Lesson 1 involved three separate tasks in which of tasks

Task 1 students ordered, ro
compared decimals.

During the first 23 minutes, the teacher posed an ordering decimal numbers task that read, "Order the following decimal numbers from smallest to largest on the number line: $1.5,1.1$, $1.96,1.65,1.37$." Once she read the directions, students were given four minutes to work independently while the teacher monitored the class, redirected off-task behavior, and complemented correct solutions. During the next 17 minutes, the teacher selected three students to share their solution to the task. Each time a student shared their solution, the class asked questions about the student's solution. The first student shared an incorrect solution (noted 1.5 as less than 1.37), while the second and third students shared correct solutions.

Task 2 During the next 19 minutes, the teacher had students complete a task where they competed based on their speed to round decimals and convert decimal fractions to decimal numbers. During the first five minutes, the teacher directed students to remember how to write decimals in a place value chart by relating decimals to money. The chart directed students to "multiply by 10 " on the whole number side and "divide by 10 " on the decimal side.

Sample exchange characteristic a of lesson 1:

Student (in reference to the chart): Why does it have the multiply by ten and divide by ten?

Teacher: Good question. Because, guess what? Ten times what equals one hundred?

Students: Ten

Teacher: Times ten - a hundred times what equals one thousand?

Teacher: So each time - each of these place values - you're increasing by - times ten. You are multiplying by ten. OK? And then this way — one divided by ten — would be one
Lesson 2

Students sit at tables in groups of four to six students ( 2 students at a table, two to three tables pushed together) all facing the front of the room. Students each have an opened notebook on the table in front of them. The walls are full of posters and notes. There is a projector at the front of the room projecting on the white board.

Lesson 2 involved three tasks all focused on comparing and ordering fractions.

During the first 11 minutes, the teacher set up the lesson. She spent three minutes discussing the learning target: compare and order fractions. Next, she spent four minutes on reviewing fraction comparison strategies (i.e., visual comparisons using drawings, benchmark comparisons, comparing numerator and denominators, placement on number line) that the class had come up with in the prior two lessons. Each of the strategies was named after the student(s) who shared them. Then, the teacher spent four minutes reviewing exit tickets (i.e., a worksheet the students fill out at the end of class with a prompt to allow the teacher to check-in on students' understanding; the exit ticket contained the problems that are being worked on this day) with students from the prior day. She summarized their responses and shared the results with students to illustrate that a large portion of the class still needed to work on fraction comparison strategies.

The next 21 minutes were spent in small groups. During the first four minutes, students individually reviewed the strategies they had used to compare fraction comparison problems on the prior two days' exit tickets. Then, students worked in pairs for 14 minutes to either (a) discuss fraction comparisons for which they have different results or (b) compare strategies they used for fraction comparisons to determine where they used different strategies. Finally, the teacher reviewed and reflected with the students on the way that students had engaged with each other for four minutes on their various strategies for and challenges with comparing fractions. 
Table 1 (continued)

Lesson 1

tenth. It will be less than one. OK, does that make sense?

The game was played in front of the whole class, and two students were given either a decimal fraction or a decimal number with a requested place value to round to (e.g., Write $11 / 100^{\text {th }}$ as a decimal. Round $325 / 100$ ths to the nearest tenth. Write $47 / 10$ ths as a decimal. Round 5.55 to the nearest whole. Write $10011 / 4^{\text {th }}$ as a decimal.) To win the competition, a student had to be the first to write the equivalent decimal on the place value chart or round the decimal number to the requested place value. Five pairs of students competed in the decimal task. The teacher explained correct answers and reminded the class about the rounding rule: "five or more, raise the score."

Task 3 During the last 19 minutes, students worked in small groups to create posters explaining their solution strategies for different story problems. In the first five of those 19 minutes, the teacher distributed posters with different story problems to each group (e.g., Today the grade 4 runners ran seventy-one hundredths $\mathrm{km}$. The grade 6 runners ran six hundred seventy-five thousandths $\mathrm{km}$. Which grade ran more?). Story problems involved rounding or comparing decimals, and students were instructed to represent the word problem and provide an explanation using a visual, words, and numbers. During the next 10 minutes, students worked on their assigned task and asked some questions. The teacher monitored the class, redirected off-task students, and assisted groups when needed. In the last four minutes, the teacher checked in with each group to determine progress and whether they had a solution. Some groups finished while others needed five more minutes.

Summary In summary, lesson 1 contained three sets of activities. In the first activity, students ordered decimals on a number line. In the second activity, students worked on rounding decimals. In the third activity, students worked in groups on a word problem involving decimal comparison.
Lesson 2

During the last 30 minutes, individual students (selected by the teacher) shared how they compared the fractions. For each strategy shared, the class was asked which of the class-generated strategies the presenting student had used. This prompt engaged students in discussing each other's mathematical thinking.

Sample exchange characteristic ${ }^{\mathrm{b}}$ of lesson 2:

Student A shared their strategy for arguing that $24 / 42$ was greater than $1 / 2$ because 24 is more than 21 , which is half of 42 . After the initial presentation, students reflected on the strategy.

Teacher: So how did you know that... that twenty-four forty-twos is more than one-half?

Student A: Because, if 21 is one-half- then because 24 is a completely different number. There's three extra to get 24. And if you have 24 plus 24 equals 48 , not 42 .

Teacher: Student B, what makes sense to you? Student B: When you asked her-if twenty-four forty-twos is greater than one-half, just because 24 is three numbers higher than the half of 42 .

Teacher: Student C, what makes sense to you?

Student C: 21 is half of 42 .

In summary, lesson 2 also contained three sets of activities; however, these three activities were closely related (i.e., setup of the activity, working on the activity, sharing out with everyone), and all three were focused on the same content goal.

\footnotetext{
a This exchange captures the type of interaction of the teacher and students focusing on procedures

${ }^{b}$ This exchange was characteristic as the teacher pushed students to explain their sense making rather than providing them with an explanation
} 
focused on video and transcripts of two lessons. The lessons occurred toward the end of the school year.

The setting for the lessons is an elementary school in a mid-sized school district in the USA. At the time of this study, the school had an enrollment of approximately 580 students with a $73 \%$ minority enrollment. Furthermore, $79 \%$ of children qualified for free or reduced lunch. At this school, $53 \%$ of 5 th graders were meeting the math standards as assessed by yearly locally mandated standardized tests. For this study, we focused on two lessons at this school, both in the fourth grade. In both classrooms, students sit at tables in groups of four to six students (2 students at a table, two to three tables pushed together) all facing the front of the room. The walls are full of posters. Several of the authors (Thanheiser, Melhuish) spent several days in these teachers' classrooms.

Both lessons had active engagement of students in the classroom, but one class lesson was primarily focused on increasing students' procedural knowledge while the other lesson was focused on students using justification to increase their mathematical understandings. Thus, we were interested in exploring and analyzing the differences in math teaching and learning in two classrooms. A brief description of the lessons and sample exchanges is provided in Table 1.

\section{Analysis of the lessons}

In selecting existing frameworks, we began with our sociocultural perspective, focusing on the essential aspects for students to engage in justifying. As noted above, this includes the task, teacher support in the whole class discussion (eliciting, supporting, extending), and student engagement.

While several frameworks exist that look at classrooms (i.e., Askew, 1997; Rowland, Huckstep, \& Thwaites, 2005), none of the existing frameworks considers all three elements (task, teacher's role, student engagement) in relation to justifying. Askew (1997), for example, examined numeracy and looked at teacher beliefs and student knowledge but not necessarily the interactions between them. Rowland's knowledge quartet (2005) foregrounds teacher knowledge. Thus, we looked at individual frameworks that would allow us to examine each of the three elements.

To examine (1) the tasks or task sequence, we integrated cognitive demand (Smith \& Stein, 1998) and lesson cohesion (Smith \& Stein, 1998; Stein \& Smith, 2011). While lesson cohesion existed as a concept, we developed levels for the purpose of this framework. To examine (2) the teacher's role in leading the mathematical discussions, we looked at both teacher support for collective argumentation (Conner et al., 2014) and student contributions related to argumentation (Melhuish et al., 2019) in those discussions. To examine (3) students or students' engagement, we examined cognitive engagement activity (Chi \& Wylie, 2014) which reflects observable behavior related to engagement with the content.

We describe each of these below and then coordinate them (Bikner-Ahsbahs \& Prediger, 2010). In tandem, these frameworks helped us identify and operationalize how the classroom cultures of students engaging in justifying varied across the two lessons. For each of the analyses, we adjusted our unit of analysis to appropriately align with selected analytic frameworks adapting methods directly from framework authors when available. For example, when coding the coherence of the lesson, cognitive demand, and cognitive engagement activity, we segmented the lesson into chunks based on the focus of the segment/task (Smith \& Stein, 1998), and then coded those segments. For collective argumentation and 
student contributions, we used the transcripts of the lesson to identify talk turns and then coded each talk turn (Conner et al., 2014). See Appendix Tables 3, 4, 5, 6, 7, 8, 9, and 10 for a full explication of these analytic methods.

\section{Examining classroom culture of students engaging in justifying lessons 1 and 2}

In the following, we use each of the frameworks to analyze each of the two lessons, and then turn to networking the frameworks to make sense of the observable differences in the justifications and generalizations in the lessons.

\subsection{Student contribution types}

The first component of our analysis focuses on student contribution type. We analyzed student contributions from the view of the relationship between the student and content to classify student contributions by type of reasoning (justifying, generalizing, or using procedures/facts.) Establishing a difference in this component was essential to evidence that there was a difference in classroom culture in terms of students' justifying.

Background and operationalization of student contribution types We focused on classifying types of student reasoning related to argumentation (Melhuish et al., 2019) in terms of contributions that rely on procedures and facts versus contributions that leverage mathematical structure and meaning to justify. This was an essential component of our analysis as it provided the evidence that there was a difference in classroom culture in terms of students' discourse reflecting justification. Justifying serves as learning practices where students not only engage in important mathematical activity but also deepen their understanding of mathematical concepts (Melhuish, Thanheiser, \& Guyot, 2018; Staples et al., 2012).

Existing frameworks emphasize types of justifications (Sowder \& Harel, 1998) and how justification develops in the classroom (Williams, 1993). In our analysis, we were interested in the distribution of student contributions and wanted a framework to describe the extent to which students engaged in the activities of justifying. Therefore, we used the Student Discourse Observation protocol (Melhuish et al., 2019) which parses student mathematical contributions into three categories: using procedures and facts, justification, or generalizations (see Fig. 1).

\begin{tabular}{|c|c|c|}
\hline PF USING PROCEDURES/FACTS & J JUSTIFYING & G GENERALIZING \\
\hline $\begin{array}{l}\text { No evidence of reasoning } \\
\text { - Short answer to a direct question } \\
\text { - Restating facts/statements/rules } \\
\text { - Showing or asking for procedures } \\
\text { Uses meanings, definitions, properties, known } \\
\text { math ideas to describe reasoning when: } \\
\text { - Explaining ideas \& methods } \\
\text { - Questioning to clarify } \\
\text { - Noticing relationships/connections } \\
\text { But doesn't show why the ideas/methods work }\end{array}$ & $\begin{array}{l}\text { Reasons with meanings of ideas, definitions, } \\
\text { math properties, established generalizations to: } \\
\text { - Show why an idea/solution is true } \\
\text { - Refute the validity of an idea } \\
\text { - Give mathematical defense for an idea } \\
\text { that was challenged }\end{array}$ & $\begin{array}{l}\text { Reasons with math properties, definitions, } \\
\text { meanings of ideas, established generalizations, } \\
\text { and mathematical relationships as the basis } \\
\text { for: } \\
\text { - Making conjectures about what might } \\
\text { happen in the general or special cases } \\
\text { or } \\
\text { - Justifying a conjecture about what will } \\
\text { happen in the general or special cases }\end{array}$ \\
\hline
\end{tabular}

Fig. 1 The Student Discourse Observation tool 
Student contributions in lesson 1 and lesson 2 If we consider our sample lesson, we can compare the nature of the student contributions. In the first lesson, almost all the student contributions were using procedures/facts including a clarification question and single-word answers. In the second lesson, a student's justification was a central focus of discourse: Student A justifying why 24/42 was greater than 1/2. Other students then engaged with this justification reflecting an increased number of justifying contributions. In the first lesson, $6 \%$ of the student contributions were classified as justifying, while in the second lesson, $19 \%$ of the contributions were classified as justifying. As such, we see justifying as a substantial part of the classroom in the second lesson.

Now that we have attended to a difference in the student-content relationship: more justifying contributions, we consider other components of the lesson that may account for classroom culture.

\subsection{Coherence of the lesson}

Coherence of the lesson focuses on a lesson's alignment with an overarching learning target (Stein \& Smith, 2011) and the degree to which the instruction is steered toward a mathematical point (Stein \& Smith, 2011). We see this component as primarily a result of the relationship between the teacher and the mathematical content, because the teacher initially plans and then enacts the lesson sequence based on mathematical content goals, ideally with an aim of justifying and/or generalizing.

Background and operationalization of lesson coherence This component focuses on the overall coherence of the lesson. Identifying a learning target can be supportive in developing a mathematically productive classroom (Remillard, 1996). Mathematically rich lessons center around a specific learning target or set of mathematics goals (Sleep, 2012). Two essential aspects of teaching toward a specific learning target or mathematics goal are as follows: identifying the goal and focusing instruction on the goal which leads to lesson coherence (Cai, Kaiser, Perry, \& Wong, 2009; Stigler \& Hiebert, 1999). By identifying a mathematical idea to understand, the measure of success of a lesson can shift away from the accurate implementation of procedures or finding answers to a deepened understanding of the mathematics underlying procedures and tasks. Lesson coherence is an important feature of implementing mathematics lessons. To orchestrate a productive discussion, "teachers need to have clear learning goals for what they are trying to accomplish in the lesson," (Stein \& Smith, 2011, p. 13), and adjust them as needed during the lesson to support the holding of high expectations for each and every student in the classroom.

With an established goal, the lesson as a whole as well as all of its parts can be examined for coherence around that goal. Some researchers have considered lesson coherence with respect to a focus on a single mathematical topic (Fernandez, Yoshida, \& Stigler, 1992; Stigler \& Perry, 1988), while others have looked at the interrelatedness of topics within a lesson (HerbelEisenmann \& Otten, 2011). Still others have, more generally, treated a coherent lesson trajectory as an important measurable aspect of mathematical quality of instruction (Charalambous \& Hill, 2012). In general, lesson coherence can provide opportunity for students to engage with mathematical ideas at the level needed for justification including being able to attend to connections and abstract "key points" (Fernandez et al., 1992, p. 123). 
Lesson coherence in lesson 1 and lesson 2 In our analysis, we developed a framework synthesizing the above research. To analyze lesson cohesion, we identify three distinct levels: (1) lesson incohesive, there are at least two distinct topics without a clear goal or connection; (2) lesson cohesive (focused on a single topic) but without a clear goal or connection; (3) lesson cohesive (focused on a single topic) with a clear goal or connection. Reflecting back to our two lessons and the transcript excerpts, we found that lesson 1 was an incohesive lesson because it included three different topics (ordering decimals, rounding decimals and converting decimal fractions into decimal notation, and word problems with various operations on decimals) without an explicit mathematical goal or connection between those topics, other than the fact that they all involved decimals. While all three topics were related to decimals, the teacher and/or the students did not make any clear connection across the segments. In contrast, lesson 2 was a cohesive lesson with an identifiable and explicitly stated content goal, compare and order fractions. The three distinct segments in lesson 2 all explicitly related to supporting students in making sense of the overall content goal, and formed one large unit with three components, including, first, launching the exploration; second, exploring; and third, discussing and summarizing.

\subsection{Cognitive demand of the task}

Cognitive demand is a reflection of how a teacher mediates the relationship between content and students. That is, the cognitive demand reflects students' opportunity to reason based on teacher-enacted tasks. Student justifying may result from high cognitive demand tasks. Students are given opportunities to justify and generalize when provided with tasks that allow them to engage with the mathematics (Stein \& Smith, 1998) in conceptual ways and support discussion and justification of their thinking (Chapin, O'Connor, \& Anderson, 2013; Staples \& Newton, 2016; Stein et al., 2008).

Background and operationalization of cognitive demand Cognitive demand describes the kind of thinking that is asked of students (Smith \& Stein, 1998). During math instruction, teacher actions can serve to diminish or maintain or increase the cognitive demand of tasks (Henningsen \& Stein, 1997). Research indicates that classrooms that support student engagement in higher-demand tasks promote greater success on measures of students' reasoning and problem solving (Boaler \& Staples, 2008; Stein, Crowley, \& Resnick, 2016). Furthermore, cognitively demanding tasks provide opportunities for students to engage in justifying (Stein et al., 2016), whereas lower cognitive demand tasks provide opportunities to reveal students' understandings of facts and procedures.

We adopt Smith and Stein's (1998) classification of low-demand and high-demand tasks. Low-demand tasks consist of those (1) focused on memorization or (2) focused on procedures without connections. High-demand tasks consist of those focused on (3) procedures with connections and (4) doing mathematics. Doing mathematics might include "explor[ing] and understand[ing] the nature of mathematical concepts" (Smith \& Stein, 1998, p. 348). A lesson can be parsed into "tasks" via identification of activity moving toward a single pedagogical goal. These tasks, as implemented, can then fall into the high or low cognitive demand categories.

Cognitive demand in lesson 1 and lesson 2 Returning to our lesson exchanges (see Table 1), the sample exchange in lesson 1, task 1 , reflects a task that involved memorization 
and procedures without connections. The teacher prompted the students to respond with memorized facts. This exchange was representative of her interaction with students in the lesson where the overall focus was on rules and procedures. In contrast, the sample exchange in lesson 2, task 3, came from a task we labeled as "doing mathematics" because the students were actively engaged in meaning-making as well as connecting the shared solutions to strategies shared the day before. Everyone was expected to engage in sense making, which can be seen when the teacher asked students to explain their sense making. The focus was on non-algorithmic thinking or understanding the nature of concepts. Throughout this segment, the teacher prompted the students with "So whisper to your neighbor what strategy you think she's using out of all of these, whose strategy?"

\subsection{Teacher support for collective argumentation}

Teacher support for collective argumentation focuses on the relationship between teacher and students where a teacher provides particular prompts and actions directed toward students' engagement in argumentation.

\section{Background and operationalization of teacher support for collective argumentation Given} that our focus was on justification and generalization, we adapted a collective argumentation framework (Conner et al., 2014). Collective argumentation involves discussions that "involve multiple people arriving at a conclusion, often by consensus" (Conner et al., 2014, p. 401). Supporting argumentation in the classroom can be quite productive for students. For example, Ing and colleagues (2015) found evidence that teacher support for student argumentation may increase student participation and achievement. Additionally, there is evidence that teacher support for student argumentation increases student reasoning and sense making (HufferdAckles, Fuson, \& Sherin, 2004; Leinhardt \& Steele, 2005). For example, Hufferd-Ackles et al. (2004) showed that a teacher's growth in questioning from obtaining correct answers to questioning to uncover students' mathematical thinking supported the development of a classroom community characterized by students engaged in reasoning, defending, and proving. Leinhardt and Steele (2005) found that a teacher whose instruction set and supported an expectation of explanation, challenge, revision, and dialogue to explore mathematical concepts promoted students' mathematical reasoning with increased frequency.

Multiple frameworks classifying teacher and student actions exist in research literature. Some focus on questioning strategies (e.g., Driscoll, 1999; Franke et al., 2009; Frey \& Fisher, 2010; Sahin \& Kulm, 2008), while others describe teacher moves that support student reasoning (e.g., Ozgur, Reiten, \& Ellis, 2015) or characterize the extent to which teacher and students are viewed as co-learners and co-teachers in a math talk community (e.g., Hufferd-Ackles et al., 2004). We selected Conner et al.'s (2014) framework because of its specific focus on questioning and other teacher actions that support collective argumentation. Their identification and descriptions of types of teacher questions, together with other actions that support collective argumentation, were useful in explicating the observed differences in the two lessons.

The collective argumentation framework provides a fine-grained analysis that first identifies contributions to collective argumentation and then characterizes the contributions, along with actions that support this argumentation. As noted by Conner et al. (2014), analyzing these teacher actions can provide insight into how to support students in argumentation. In general, 
this framework parses teacher contributions into question types and supportive action types. For example, a question might be requesting a factual answer, that is "Asks students to provide a mathematical fact" (p. 418) or requesting an idea, that is "Asks students to compare, coordinate, or generate mathematical ideas" (p. 418).

Teacher support for collective argumentation in lesson 1 and lesson 2 In our two focal lessons, we found that the teacher questions in lesson 1 were mostly focused on requesting a fact, such as "Times ten - a hundred times what equals one thousand?" In total, 63\% of teacher requests during this lesson were requesting facts. In contrast, this number dropped to $10 \%$ for lesson 2. During the second lesson, the teacher questions were focused on requesting elaboration, "So how did you know that 21- sorry- how did you know that twenty-four forty-two's is more than one-half?" and requesting an idea, "What makes sense to you?" In this second lesson, $38 \%$ of teacher requests were requests for an idea as opposed to only $5 \%$ in the first lesson.

\subsection{Cognitive engagement activity}

The last relationship we consider is that of cognitive engagement. Cognitive engagement captures the nature of student interactions with the content and with each other. We chose this framework to analyze the differences in students' engagement in the lesson, independent of the quality or nature of their activity. This allowed us to focus on how the lessons were different and to later reason about which activities seem to support or limit students' engagement in justifying.

Background and operationalization of cognitive engagement activity Cognitive engagement refers to the cognitive level of student activity as identified through observable behaviors. As addressed in our underlying theoretical assumptions, we focus on social analogs of cognitive engagement that can be observed in how students engage in classroom activity. Student participation interaction with lesson/content and with each other's ideas about content can range from passively listening to instruction to rich mathematical interactions between peers and/or the teacher in which students are actively constructing knowledge and reasoning about mathematics. Chi and Wylie (2014) describe four levels of cognitive engagement activity: interactive, constructive, active, and passive. Passive engagement describes students who receive instruction but are not overtly cognitively engaged in any activity. At this level, students may be listening or reading without taking notes, summarizing, or interacting with manipulatives. Active engagement describes students who engage, for example, by repeating and copying solution steps. Constructive engagement describes students who engage with the material beyond the teacher-prompted steps, illustrated by students asking their own questions, posing their problems, comparing and contrasting cases themselves, and integrating ideas from various solutions. Interactive engagement describes students who are engaged with the material by dialoguing with peers where the students engaged are engaging constructively, such as discussing the validity of a justification within a small or large group. In Chi and Wylie's (2014) work, they hypothesize that different engagements link to different knowledgechange processes and document that each level corresponds to increased gains in knowledge for students. From our perspective, the most pertinent parts of this framework are the role that constructive and ultimately interactive engagement can play in students co-constructing 
knowledge with "[d]ebating with a peer about the justifications" (Table 1), being one of the observable indicators of interactive engagement. Students would need to engage constructively and interactively in order to produce mathematical justifications.

Cognitive engagement in lesson 1 and lesson 2 If we return to our sample exchanges, lesson 1 reflects students with passive or active cognitive engagement. For example, they engaged by providing anticipated short answers. In the first lesson, students engaged at the passive or active level for $92 \%$ of the time. Lesson 2 reflects a constructive mode of engagement, where students were engaged with making sense of and applying one of many solution strategies suggested in the class. In the second lesson, students engaged at the constructive/interactive level $82 \%$ of the time.

\section{Gaining insight from networking the five frameworks}

Researchers have argued that "combinations of different frameworks can help in better capturing instructional complexity" (Charalambous \& Praetorius, 2018, p. 359) and that several frameworks are needed to explain mathematics teaching and learning, a "multi-faceted phenomenon" (Bikner-Ahsbahs \& Prediger, 2006, p. 484). By networking, we used the five frameworks described above to analyze the same classrooms in order to understand high-quality mathematics classrooms focused on engaging students in justifying. Each of the frameworks provided a lens to examine one aspect of a mathematics classroom (connected to a core relationship between teachers, students, and content) which may account for a culture of justifying. Taken together, the coordination of frameworks allowed us to see a picture of the mathematics classroom focused on engaging students in justifying that we might not have been able to see with analyzing our data using just one of the frameworks (Bikner-Ahsbahs \& Prediger, 2006; Charalambous \& Praetorius, 2018; Tabach et al., 2020). Thus, we consider the variety of frameworks provided us with a "resource for grasping complexity that is scientifically necessary" (Bikner-Ahsbahs \& Prediger, 2010, p. 489) to explain differences we noticed in the two lessons. From a research perspective, there was value in considering the various individual frameworks. By focusing on the individual frameworks, we were able to code the data in a meaningful way, from multiple perspectives. However, it is through networking these frameworks that we can better see and understand the complex nature and consequences of the teaching and learning happening in each classroom.

Through existing framings, such as the instructional triangle, researchers have argued that classroom instruction reflects complex and interdependent relationships between teacher, student(s), and content (e.g., Cohen, Raudenbush, \& Ball, 2003; Hawkins, 2002; Lampert, 2001). The instructional triangle has been posited as a means to theorize high-quality instruction via attention to the complex relationships between teacher/teaching, students/learning, and content. Yet, when studying the effectiveness of mathematics classrooms, most analyses focused on a subset of the vertices or edges within the instructional triangle (Charalambous \& Praetorius, 2018). Similarly, most observation tools have their key focus on the teacher (Praetorius \& Charalambous, 2018). 


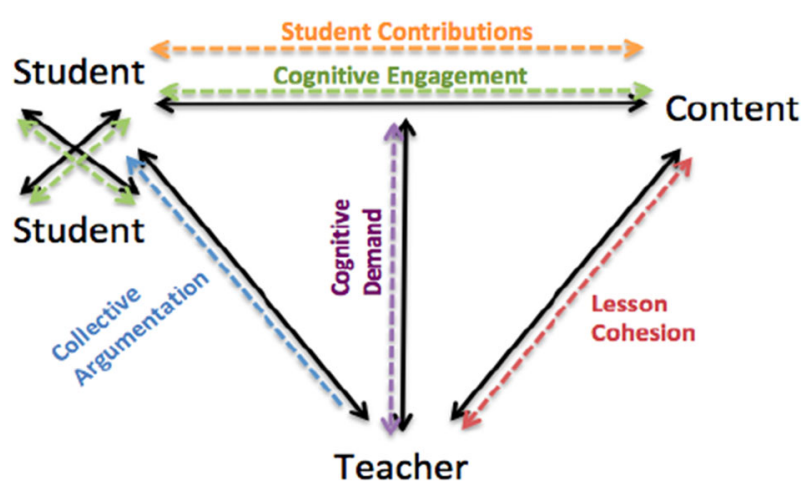

Fig. 2 Networking the five frameworks into one framework to examine high-quality mathematics classrooms focused on engaging students in justifying

We utilize the structure of the instructional triangle as a means to coordinate varying frameworks that illustrate the observable relationships between teacher, students(s), and content networking the frameworks along its edges. Our analysis focused (1) on the relationship between student and content via student contribution types, (2) teacher and content via lesson cohesion, (3) teachers' shaping student content engagement via cognitive demand; (4) students and students and teacher via collective argumentation; and (5) student-student and content via student cognitive engagement activity (see Fig. 2). As such, the five individual frameworks form a coherent whole to examine high-quality mathematics classrooms focused on engaging students in justifying.

Juxtaposing a network of frameworks on the instructional triangle also addresses calls to incorporate the social aspect of teaching and learning into the instructional triangle (Rezat \& Sträßer, 2012; Schoenfeld, 2012) as Schoenfeld inquired, "What cultural properties must the mathematics classroom have in order for students to develop mathematically productive understandings of the discipline?" (p. 594) Schoenfeld called for "the development of analytic tools and techniques that would enable us to elaborate the cultural phenomena identified here, and the use of such understandings to design richer mathematical classroom experiences for our children." (p. 598). In addressing this call, we intentionally focused on the relationships between the nodes rather than on just the nodes (Askew, 1997) or on one of the nodes and the adjacent relationships (Rowland et al., 2005). In the next section, we instantiate how the networked frameworks provided insight into the justifying classroom culture.

\subsection{Overall lesson analysis: applying the network of frameworks}

In the lesson 1 sample exchange, the teacher's support for collective argumentation positioned students to engage with the mathematical content in a relatively superficial way. Their contributions were factual and situated in the lower mode of active engagement. As a result, the cognitive demand of the task also reflected low demand. The surface level treatment of ideas may also tie into lesson cohesion, where a lack of a cohesive goal impacted instructional decisions and may have prevented students from having opportunity to abstract and make meaningful mathematical connections. 
Lesson 1

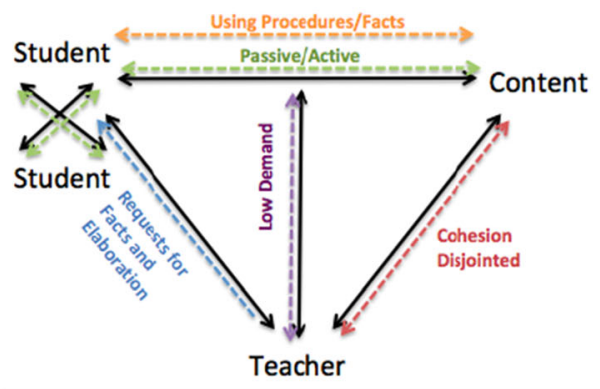

Lesson 2

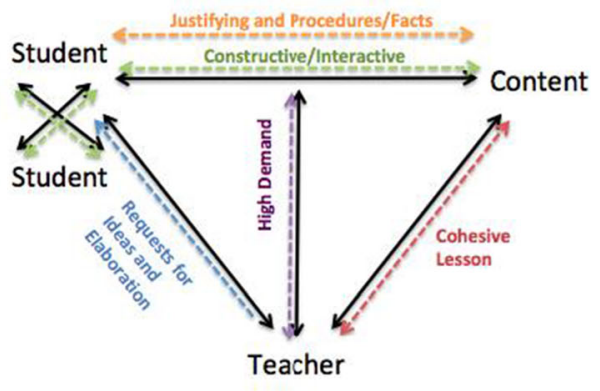

Fig. 3 Instructional triangles for each of the two lessons

In contrast, the lesson 2 sample excerpt contained very different types of teacher questions and supportive actions that were more open and prompted students to engage with ideas and justify their thinking. Such thinking reflects the high cognitive demand of the task and deep attention to the learning goal. In both lessons, the teacher asked questions related to mathematical content, and the students provided contributions; however, the nature of the relationship among the teacher, student, and content was noticeably different (see Fig. 3 for a comparison of the lessons on the triangle).

\subsection{Comparing lessons}

The sample exchanges situated within the lesson descriptions were reflective of the lessons as a whole. By zooming out, we can look at the overall trends in the instructional triangle (see Table 2). With respect to the Teacher-Content Relationship, in lesson 1, the lesson contained three distinct mathematical topics with no discernable learning goal. In lesson 2, the lesson was coherent, tasks organized around a single topic and aligned with an explicitly stated learning goal. Lesson 2 also had a clear introduction/launch to the task and included collaborative problem solving, and the lesson concluded with a discussion during which students were encouraged to justify and generalize.

With respect to the teacher mediating the content-student relationship, the student-content relationship, and the student-student-content relationship in lesson 1, the student contributions were nearly all using procedures and facts, with cognitive demand reflecting procedures without connections, and the cognitive engagement was either passive or active. In contrast, lesson 2 had a statistically significant higher number of justifications from students, higher levels of cognitive demand, and constructive or interactive levels of cognitive engagement.

With respect to the teacher-student relationship, the teacher's question types were also noticeably different with requesting a fact dominating the first lesson and requesting an idea as the most frequent teacher question type in the second lesson. This shift in collective argumentation questioning appeared to support students in more meaningful engagement with the mathematical content. In the second lesson, students engaged in a rich exploration of one mathematical topic via engaging with each other's ideas and building mathematical justifications, while in the first lesson, students jumped from topic to topic and task to task, and primarily contributed procedures and facts in their interactions. Furthermore, they were not interactively engaging with each other. 


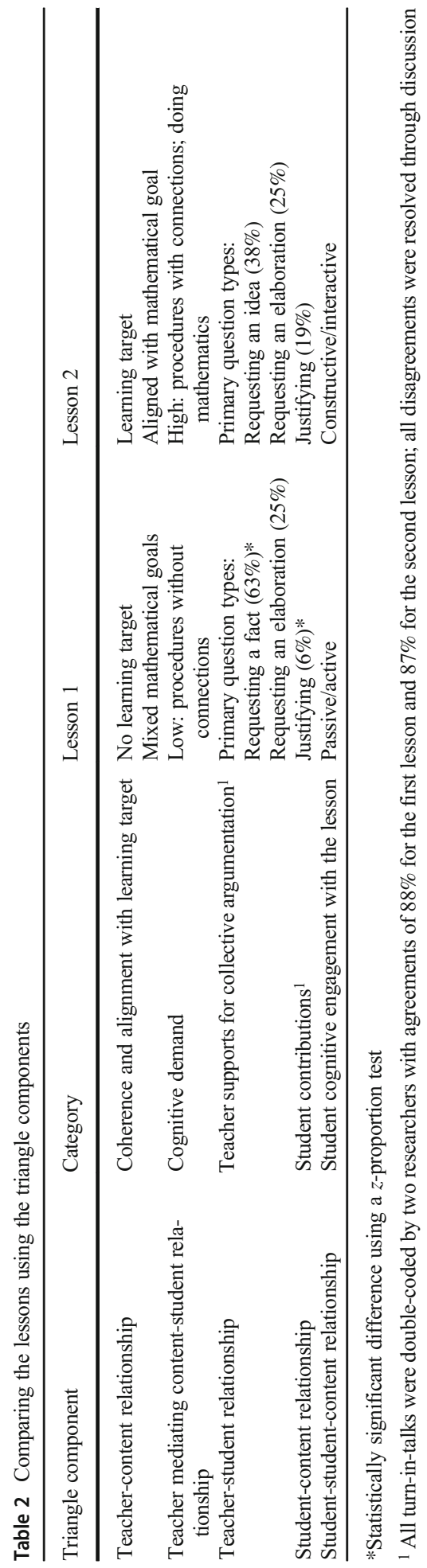




\section{Discussion}

By networking the five frameworks of lesson cohesion (Smith \& Stein, 1998; Stein \& Smith, 2011), cognitive demand (Smith \& Stein, 1998), collective argumentation (Conner et al., 2014), student contributions related to argumentation (Melhuish et al., 2019), and cognitive engagement (Chi \& Wylie, 2014) along the instructional triangle, we were able to explore the, at times, interdependent relationships between and among the teacher, student(s), and content in these two math lessons, enabling us to explore the relationships along the edges of the instructional triangle. Thus, we were able to meaningfully operationalize the relational arrows of the instructional triangle with an overarching lens for justification classroom culture through the use of multiple frameworks.

We contend that one of the most powerful insights from this coordination of frameworks into the reconceived instructional triangle with measurable components is that it allowed us to parse apart the complexity of classroom cultures focusing on students engaging in justifying. Each framework individually told us something about the lessons. For example, when comparing the two lessons (Fig. 3), we see that each of the component frameworks along the arrows of the triangle differ across the two lessons. Notably, given our focus on eliciting student reasoning, the difference in the level of student justification from lesson 1 to lesson 2 was a statistically significant increase.

Yet, these frameworks do not work disjointedly, rather, they work in relationship with each other. All frameworks capture a component of the classroom that may reflect or contribute to a culture of justification, and thus, a change in one part of the framework has the potential to affect changes in the others. For example, the difference in teacher questioning toward requests for ideas and elaborations appeared to support students in lesson 2 in deeper engagement with the content and each other, which may account for the increase in justification contributions. It was by examining both the individual components and then the whole of the lessons that we gained a more complete picture of the actions and interactions that supported more highquality mathematics instruction in the second lesson than the first.

It must be noted that we intentionally selected the component frameworks for this analysis based on extant literature documenting elements of high-quality mathematics instruction with a focus on a classroom culture that is characterized by students engaging in justifying (e.g., Ball, 1993; Jacobs \& Spangler, 2017; Nasir \& Cobb, 2006; Schoenfeld, 2011; Turner et al., 2013). We found these frameworks to be fruitful in carefully analyzing these two case study lessons. However, analyzing different classrooms with different characteristics could provide more insight into the complexities of the teacher-student(s)-content instructional relationships and, particularly, how these varying frameworks may work in concert with one another and in tandem with the instructional triangle. Moreover, we recognize that these five frameworks are not the only elements of high-quality mathematics instruction, and that there may be other frameworks that could be networked using the instructional triangle to explore other relationships in the teacher, student(s), and content connections.

We also note that the lessons we compared were implemented by the same teacher, before and after participation in a 3-year Professional Development (PD). The PD focused on the Mathematical Habits of Mind and Interaction (Melhuish \& Thanheiser, 2017; Teachers Development Group, 2013), in conjunction with the Mathematically Productive Teaching Routines (Melhuish \& Thanheiser, 2017; Teachers Development Group, 2013) which support student engagement in the justifying. We share this information here to not only share the authentic context but also note that the goal of this paper was to focus on a method to compare the quality of math instruction rather than the change in one teacher's practice. 


\section{Conclusion}

Enacting high-quality mathematics instruction where students' voices and reasoning are elicited, valued, and used to move instruction and learning forward is a complex endeavor. This complexity cannot be fully explained by a single framework; therefore, our goal was to explore how a networking of frameworks could be used to analyze instruction in two separate lessons where the engagement of student voices, thinking, and mathematical reasoning varied. In particular, we wanted to account for our observation of different culture in regard to justifying. By analyzing and comparing and contrasting this pair of lessons, we did not seek to disparage one lesson over the other. Rather, we sought to untangle the complex relationships between teacher, student(s), and content that reflect classroom culture in an effort to better understand how and why the student reasoning varied in the two lessons.

Moving forward, we hope that this networking of frameworks as a tool for analysis and, potentially, reflection, could be used to support teachers in learning about, enacting, and refining the multiple practices needed for high-quality mathematics instruction leading to students' engagement in justification and generalization. The act of teaching is highly complex, and we argue that it is through the concrete operationalization of frameworks that mathematics educators can provide teachers with traction and opportunity to learn and reflect on practice. Furthermore, such operationalization can be powerful for researchers who are looking to describe, compare, and analyze variations among mathematics classrooms. We advocate for approaches that do not just look at students, teachers, or content in isolation but rather consider the interconnectedness of these various relationships.

\section{Appendix}

Table 3 A full explication of analytic methods

\begin{tabular}{|c|c|c|}
\hline Coding category & Coding process & Code definitions \\
\hline Lesson cohesion & $\begin{array}{l}\text { After coding the entirety of the lessons, } \\
\text { we analyzed lesson cohesion by } \\
\text { identifying three distinct levels: } \\
\text { lesson incohesive, lesson cohesive } \\
\text { without a clear goal, or lesson } \\
\text { cohesive with a clear goal. }\end{array}$ & $\begin{array}{l}\text { 1. Lesson incohesive: There are at least } \\
\text { two distinct topics the goal for the } \\
\text { topics is not clear } \\
\text { 2. Lesson cohesive without a clear } \\
\text { goal: focused on a single topic but } \\
\text { without a clear goal } \\
\text { 3. Lesson cohesive with a clear goal: } \\
\text { focused on a single topic with a } \\
\text { clear goal. }\end{array}$ \\
\hline $\begin{array}{l}\text { Cognitive demand } \\
\text { Henningsen \& Stein, 1997; Stein \& } \\
\quad \text { Smith, } 1998\end{array}$ & $\begin{array}{l}\text { Each lesson transcript was separated } \\
\text { into segments represented by a shift } \\
\text { in the focus of the lesson (e.g., } \\
\text { discussing the learning target or } \\
\text { reviewing strategies) or a shift from } \\
\text { group discussion to private } \\
\text { reasoning time to partner sharing. } \\
\text { For each segment, we then } \\
\text { identified the extent to which } \\
\text { students were applying rules they } \\
\text { memorized (low 1), performed } \\
\text { procedural tasks without engaging } \\
\text { in the conceptual ideas of the }\end{array}$ & $\begin{array}{l}\text { 1. Low } 1 \text { Memorization: Involves } \\
\text { either reproducing previously } \\
\text { learned facts, rules, formulas, or } \\
\text { definitions or committing facts, } \\
\text { rules, formulas, or definitions to } \\
\text { memory. Cannot be solved using } \\
\text { procedures because a procedure } \\
\text { does not exist or because the time } \\
\text { frame in which the task is being } \\
\text { completed is too short to use a } \\
\text { procedure. Such tasks are not } \\
\text { ambiguous, and involve the exact } \\
\text { reproduction of previously seen }\end{array}$ \\
\hline
\end{tabular}


Table 3 (continued)

\section{Coding category}

Coding process

procedures they were using (low 2), used procedures with engagement in conceptual ideas (high 3), or engaged in tasks in which they explore mathematical ideas and make connections within and between mathematical ideas (high 4) (see Tables 4 and 5 for examples of segments with coding). After coding each segment, we assigned an overall code for the whole lesson, reflecting the primary nature of the mathematics the student engaged in.
Code definitions

material. Have no connection to the concepts or meaning that underlie the facts, rules, formulas, or definitions being learned or reproduced.

2. Low 2 Procedures without connections: Are algorithmic. Use of the procedure is specifically called for or is evident from prior instruction, experience, or placement of the task. Require limited cognitive demand for successful completion. Little ambiguity exists about what needs to be done and how to do it. Have no connection to the concepts or meaning that underlie the procedure being used. Are focused on producing correct answers instead of on developing mathematical understanding. Requires no explanations or explanations that focus solely on describing the procedure that was used.

Example: (Lesson 1 task 1) Students were asked to use a number line to compare decimals. When they shared their solutions, the teacher instructed them to convert decimals to the same place value to compare decimals, stating that "right now we still need to convert to the same place value. As you do more work with decimals - it will be easier for you to order them even without converting them - cause you'll be so familiar."

3. High 3 Procedures with connections: Focus students' attention on the use of procedures for the purpose of developing deeper levels of understanding of mathematical concepts and ideas. Suggests explicitly or implicitly pathways to follow that are broad general procedures that have close connections to underlying conceptual ideas. Usually are represented in multiple ways (e.g., visual diagrams, manipulatives, symbols, and problem situations), and making connections among multiple representations helps develop meaning. Requires some degree of cognitive effort. Although general procedures may be followed, they cannot be followed mindlessly. Students need to engage with conceptual ideas that underlie the procedures to complete the task successfully and that develop understanding. 
Table 3 (continued)

Coding category $\quad$ Coding process $\quad$ Code definitions

4. High 4 Doing mathematics: Requires complex and non-algorithmic thinking - a predictable, well-rehearsed approach or pathway is not explicitly suggested by the task, task instructions, or a worked-out example. Requires students to explore and understand the nature of mathematical concepts, processes, or relationships. Demands self-monitoring or self-regulation of one's own cognitive processes. Requires students to access relevant knowledge and experiences and make appropriate use of them in working through the task. Requires students to analyze the task and actively examine task constraints that may limit possible solution strategies and solutions.

Example: (Lesson 2, segment 3.1) Students were asked to compare fraction comparison strategies. Students were expected to explain their thinking, explore multiple strategies, and make sense of multiple strategies. In monitoring students' discussions, the teacher repeatedly asks, "Why does it work mathematically? Kind of going deeper and thinking about justifying. [Discuss] Why this strategy works."

Cognitive engagement

Chi and Wylie's (2014) framework with four levels of engagement: passive, active, constructive, and interactive
Coders used the same lesson segmenting procedure as was used for cognitive demand coding (see Tables 4 and 5 for examples of segments with coding). Each segment was coded by two coders, and any discrepancies were resolved through discussion.
1. Passive engagement: Students' attention may have been focused on specific mathematical content, but they do not exhibit any physical gestures, e.g., record notes or their thinking, asking or answering questions.

Example: (Lesson 2 Segment 1.2) The students quietly listened while Hannah reviewed the class' previously generated fraction comparison strategies.

2. Active engagement: Students provided verbal and written responses to prompts or questions from the teacher, but they did not ask questions or explain their solutions.

Example: (Lesson 1 Segment 2.2) Students recorded solutions to given prompts and provided verbal answers to Hannah's questions.

3. Constructive engagement: If there were multiple instances of students asking questions and offering explanations to each other in peer dialogue. However, this was characteristic neither of the entire 
Table 3 (continued)

\begin{tabular}{ll}
\hline Coding category & Coding process
\end{tabular}

class nor of the entire segment.

Note, in a few cases, this was coded as interactive/constructive.

Example: (Lesson 1 Segment 1.3)

$J$ : And then I went one and one fifth, one and five tenths, and then - one and thirty-seven hundredths - and one and sixty-five hundredths - one and ninety-six hundredths.

Teacher: OK, thank you. Alright, questions or comments for J?

$C$ : Since one and five tenths is equivalent to one and fifty hundredths - why does one and thirty-seven hundredths - why did you write one and thirty-seven hundredths is greater than one and fifty hundredths?

4. Interactive engagement: When there was dialogue between partners, comparing solutions and defending and justifying their explanation.

Example: (Lesson 2 Segment 2.2)

Students working in pairs to discuss their use of fraction comparison strategies. Throughout this segment, students make statements like "I disagree with you. You can't always... what happens if she does that?" These statements together with Hannah's prompt to "compare your work... then find one problem that is different... figure out who is right and who is wrong, or-why that strategy worked... Why does it work mathematically?" provide sufficient evidence that students are dialoguing with their partners about their solutions, strategies, and justifying why their solutions make sense mathematically.

Collective argumentation

Conner et al.'s (2014) framework for teacher support of collective argumentation
First, we identified talk turns as the unit of analysis. One author read through the transcripts multiple times, identifying each talk turn and reviewing the divisions for accuracy and consistency. Talk turns were separated by a switch in speaker or when a speaker talked to a new individual(s). Utterances that served to move the conversation along (i.e., "speak up" or "face the class") were not considered a switch in speaker. A second researcher then confirmed the designation of talk turns. Next, each teacher talk turn was double-coded as a question or action supporting collective argumentation using Conner et al.'s (2014) framework (see Table 6, 7, 8, and 9) for a summary of question types and supportive actions). All
1. Question types and description:

Requesting a factual answer: Asks students to provide a mathematical fact.

Requesting an idea: Asks students to compare, coordinate, or generate mathematical ideas.

Requesting a method: Asks students to demonstrate or describe how they did something.

Requesting elaboration: Asks students to elaborate on some idea, statement, or diagram.

Requesting evaluation: Asks students to evaluate a mathematical idea.

Requesting clarification: Asks students if their ideas were stated accurately. Requesting revoicing: Asks students to revoice the thinking that has been shared by another student. 
Table 3 (continued)

\begin{tabular}{ll}
\hline Coding category & Coding process \\
\hline & $\begin{array}{l}\text { disagreements were resolved } \\
\text { through discussion. }\end{array}$ \\
& \\
Student contributions & \\
course observation protocol & \\
& \\
Coders used the established talk turns \\
from the collective argumentation \\
analysis to begin the student \\
contributions analysis. Each student \\
talk turn was coded as not a \\
contribution to the mathematical \\
argument (NC) or as a direct con- \\
tribution (DC) to the mathematical \\
argument. Each direct contribution \\
was then double-coded using the \\
Student Discourse Observation pro- \\
tocol (see Table 10 for a summary \\
of student contributions across \\
segments).
\end{tabular}

Code definitions

2. Other supportive action types and description

Directing: Actions that serve to focus the students' attention and/or the argument.

Promoting: Actions that serve to support mathematical exploration.

Evaluating: Actions that center on the correctness of the mathematics.

Informing: Actions that provide information for the argument.

Repeating: Actions that repeat what has been or is being stated.

1. Using procedures and facts: No evidence of reasoning (e.g., short answers to a direct question, restating facts/statements/rules, or showing or asking for procedures). Uses meanings, definitions, properties, and known math ideas to describe reasoning (explaining ideas and methods, questioning to clarify, and/or noticing relationships/connections) but does not show why the ideas/methods work.

Example: (Lesson 2) A student working on the claim that 24/42>1/2 stated, "So when I drew the number line and I drew one-half I looked at the 2 on the bottom of the one-half."

2. Justifying: Reasons with meanings of ideas, definitions, math properties, established generalizations to show why an idea/solution is true, refute the validity of an idea, and/or give mathematical defense for an idea that was challenged.

Example: (Lesson 2) The student working on the claim that 24/42 > $1 / 2$ stated, "And I knew that since there was two different pieces, I divided each of them by two, and I got 21. And since the numerator was 24, I knew that- since the numerator was 24 I knew that ... it's greater than ... cause it's above the half of 42."

3. Generalizing: Reasons with math properties, definitions, meanings of ideas, established generalizations, and mathematical relationships as the basis for making conjectures about what might happen in the general or special cases OR justifying a conjecture about what will happen in the general or special cases. 
Table 4 Timeline of lesson 1 with coding

\begin{tabular}{|c|c|c|c|c|c|}
\hline \multirow[t]{2}{*}{$\begin{array}{l}\text { Order decimal } \\
\text { numbers on a } \\
\text { number line }\end{array}$} & 1.1 & $2 \min$ & $\begin{array}{l}\text { Task setup. Task: Order the following } \\
\text { decimal numbers from smallest to largest } \\
\text { on the number line: } 1.5,1.1,1.96,1.65 \text {, } \\
\text { 1.37. } \\
\text { Teacher in front has student read out } \\
\text { directions. }\end{array}$ & Passive & Low-2 \\
\hline & 1.2 & $4 \mathrm{~min}$ & $\begin{array}{l}\text { Students work independently while Hannah } \\
\text { monitors class, redirects off-task } \\
\text { students, and compliments correct work. } \\
\text { Students work on their own. }\end{array}$ & Active & Low-2 \\
\hline \multirow[t]{2}{*}{$\begin{array}{l}\text { Round/write decimal } \\
\text { numbers game }\end{array}$} & 2.1 & $5 \mathrm{~min}$ & $\begin{array}{l}\text { Task setup: decimal competition. Hannah } \\
\text { directs students to remember how to } \\
\text { write decimals in a place value chart. For } \\
\text { the competition, two students are given } \\
\text { either a mixed number or a decimal } \\
\text { number with a requested place value. The } \\
\text { first student to write the equivalent } \\
\text { decimal on the place value chart, or to } \\
\text { round the decimal number to the } \\
\text { requested place value, wins the } \\
\text { competition. } \\
\text { Whole class. }\end{array}$ & Passive & Low-2 \\
\hline & 2.2 & $14 \min$ & $\begin{array}{l}\text { Five pairs of students compete in the decimal } \\
\text { competition. Hannah explains correct } \\
\text { answers and reminds the class about the } \\
\text { rounding rule: "five or more, raise the } \\
\text { score". Tasks: Write } 11 / 100 \text { th as a } \\
\text { decimal, round } 325 / 100 \text { ths to the nearest } \\
\text { tenth, write } 47 / 10 \text { ths as a decimal, round } \\
\text { 5.55 to the nearest whole, Write } 1001 \\
1 / 4 \text { th as a decimal. } \\
\text { Whole class. }\end{array}$ & Active & Low-2 \\
\hline $\begin{array}{l}\text { Decimal number } \\
\text { story problems }\end{array}$ & 3.1 & $5 \min$ & $\begin{array}{l}\text { Task setup. Hannah distributes posters with } \\
\text { different story problems to each group. } \\
\text { Story problems involve rounding or } \\
\text { comparing decimals and students are } \\
\text { instructed to represent the word problem } \\
\text { and provide an explanation using a } \\
\text { visual, words, and numbers. Sample task: } \\
\text { Today the grade } 4 \text { runners ran } \\
\text { seventy-one hundredths km. The grade } 6 \\
\text { runners ran six hundred seventy-five } \\
\text { thousandths km. Which grade ran more? } \\
\text { Whole class. }\end{array}$ & Passive & Low-2 \\
\hline
\end{tabular}


Table 4 (continued)

\begin{tabular}{|c|c|c|c|c|c|}
\hline Content & Segment & Time & Content of segments & $\begin{array}{l}\text { Cognitive } \\
\text { demand }\end{array}$ & $\begin{array}{l}\text { Cognitive } \\
\text { engagement }\end{array}$ \\
\hline
\end{tabular}

they have a solution. Some groups have

finished, some need five more minutes.

Small groups.

Table 5 Timeline of lesson 2 with coding

\begin{tabular}{|c|c|c|c|c|c|}
\hline & Segment & Time & Content of segments & $\begin{array}{l}\text { Cognitive } \\
\text { demand }\end{array}$ & $\begin{array}{l}\text { Cognitive } \\
\text { engagement }\end{array}$ \\
\hline \multirow[t]{3}{*}{$\begin{array}{l}\text { Setup of the } \\
\text { lesson }\end{array}$} & 1.1 & $3 \min$ & $\begin{array}{l}\text { Discussion of learning target compare } \\
\quad \text { and order fractions } \\
\text { Whole class. }\end{array}$ & N/A & Passive \\
\hline & 1.2 & $4 \min$ & $\begin{array}{l}\text { Hannah reviews class-generated fraction } \\
\text { comparison strategies (visual com- } \\
\text { parisons using drawings, benchmark } \\
\text { comparisons, comparing numerator } \\
\text { and denominators, placement on } \\
\text { number line) the class has come up } \\
\text { with in the prior } 2 \text { lessons. Each } \\
\text { strategy is named after the students } \\
\text { who shared it. } \\
\text { Whole class. }\end{array}$ & N/A & Passive \\
\hline & 1.3 & $4 \min$ & $\begin{array}{l}\text { Hannah reviews with the students how } \\
\text { they did on exit tickets on the prior } 2 \\
\text { days (the exit tickets contained } \\
\text { fraction comparison task) } \\
\text { Whole class. }\end{array}$ & N/A & Active \\
\hline \multirow[t]{3}{*}{$\begin{array}{l}\text { Small group } \\
\text { engagement }\end{array}$} & 2.1 & $4 \min$ & $\begin{array}{l}\text { Private think time-Students review the } \\
\text { strategies they used to compare frac- } \\
\text { tion comparison problems on the } \\
\text { prior } 2 \text { days (exit tickets) } \\
\text { Individual work. }\end{array}$ & High-3 & Active \\
\hline & 2.2 & $14 \mathrm{~min}$ & $\begin{array}{l}\text { Students work in pairs to either (a) dis- } \\
\text { cuss fraction comparisons for which } \\
\text { they have different results or (b) } \\
\text { compare strategies they used for } \\
\text { fraction comparisons to determine } \\
\text { where they used different strategies } \\
\text { Small group work. }\end{array}$ & High-4 & Interactive/constructive \\
\hline & 2.3 & $3 \mathrm{~min}$ & $\begin{array}{l}\text { Students review the habits of mind and } \\
\text { habits of interaction they were } \\
\text { engaged in } \\
\text { Whole class. }\end{array}$ & N/A & Constructive \\
\hline $\begin{array}{l}\text { Whole class } \\
\text { engagement }\end{array}$ & 3.1 & $30 \mathrm{~min}$ & $\begin{array}{l}\text { Individual students (selected by Hannah) } \\
\text { share how they compared fractions. } \\
\text { For each strategy, the class is asked } \\
\text { which of the strategies reviewed at } \\
\text { the beginning the student used. } \\
\text { Students discuss mathematical } \\
\text { thinking. } \\
\text { Whole class. }\end{array}$ & High-4 & Interactive/constructive \\
\hline
\end{tabular}


Table 6 Questioning types across segments in instances

\begin{tabular}{|c|c|c|c|c|c|c|c|c|}
\hline \multirow{2}{*}{$\begin{array}{l}\text { Questioning type } \\
\text { instances }\end{array}$} & \multicolumn{4}{|l|}{ Lesson 1} & \multicolumn{4}{|l|}{ Lesson 2} \\
\hline & $\begin{array}{l}\text { Segment } \\
1\end{array}$ & $\begin{array}{l}\text { Segment } \\
2\end{array}$ & $\begin{array}{l}\text { Segment } \\
3\end{array}$ & Total & $\begin{array}{l}\text { Segment } \\
1\end{array}$ & $\begin{array}{l}\text { Segment } \\
2\end{array}$ & $\begin{array}{l}\text { Segment } \\
3\end{array}$ & Total \\
\hline Requesting fact & 20 & 20 & 0 & 40 & 0 & 2 & 7 & 9 \\
\hline Requesting an idea & 3 & 0 & 0 & 3 & 0 & 6 & 28 & 34 \\
\hline Requesting a method & 2 & 1 & 0 & 3 & 0 & 0 & 6 & 6 \\
\hline Requesting elaboration & 14 & 2 & 0 & 16 & 0 & 9 & 13 & 22 \\
\hline Requesting evaluation & 1 & 0 & 0 & 1 & 0 & 1 & 3 & 4 \\
\hline Requesting clarification & 1 & 0 & 0 & 1 & 0 & 2 & 8 & 10 \\
\hline Requesting revoicing & 0 & 0 & 0 & 0 & 0 & 0 & 4 & 4 \\
\hline Total & 41 & 23 & 0 & 64 & 0 & 20 & 69 & 89 \\
\hline
\end{tabular}

Table 7 Questioning types across segments in percent

\begin{tabular}{|c|c|c|c|c|c|c|c|c|}
\hline \multirow{2}{*}{$\begin{array}{l}\text { Questioning type } \\
\text { percent }\end{array}$} & \multicolumn{4}{|l|}{ Lesson 1} & \multicolumn{4}{|l|}{ Lesson 2} \\
\hline & $\begin{array}{l}\text { Segment } \\
1\end{array}$ & $\begin{array}{l}\text { Segment } \\
2\end{array}$ & $\begin{array}{l}\text { Segment } \\
3\end{array}$ & Total & $\begin{array}{l}\text { Segment } \\
1\end{array}$ & $\begin{array}{l}\text { Segment } \\
2\end{array}$ & $\begin{array}{l}\text { Segment } \\
3\end{array}$ & Total \\
\hline Requesting fact & 49 & 87 & 0 & 63 & 0 & 10 & 10 & 10 \\
\hline Requesting an idea & 7 & 0 & 0 & 5 & 0 & 30 & 41 & 38 \\
\hline Requesting a method & 5 & 4 & 0 & 5 & 0 & 0 & 9 & 7 \\
\hline Requesting elaboration & 34 & 9 & 0 & 25 & 0 & 45 & 19 & 25 \\
\hline Requesting evaluation & 2 & 0 & 0 & 2 & 0 & 5 & 4 & 4 \\
\hline Requesting clarification & 2 & 0 & 0 & 2 & 0 & 10 & 12 & 11 \\
\hline Requesting revoicing & 0 & 0 & 0 & 0 & 0 & 0 & 6 & 4 \\
\hline Total & 100 & 100 & 0 & 100 & 0 & 100 & 100 & 100 \\
\hline
\end{tabular}

Table 8 Supportive actions across segments in instances

\begin{tabular}{|c|c|c|c|c|c|c|c|c|}
\hline \multirow{2}{*}{$\begin{array}{l}\text { Supportive action type } \\
\text { instances }\end{array}$} & \multicolumn{4}{|l|}{ Lesson 1} & \multicolumn{4}{|l|}{ Lesson 2} \\
\hline & $\begin{array}{l}\text { Segment } \\
1\end{array}$ & $\begin{array}{l}\text { Segment } \\
2\end{array}$ & $\begin{array}{l}\text { Segment } \\
3\end{array}$ & Total & $\begin{array}{l}\text { Segment } \\
1\end{array}$ & $\begin{array}{l}\text { Segment } \\
2\end{array}$ & $\begin{array}{l}\text { Segment } \\
3\end{array}$ & Total \\
\hline Directing actions & 4 & 5 & 0 & 9 & 0 & 2 & 4 & 6 \\
\hline Promoting actions & 9 & 1 & 0 & 10 & 1 & 8 & 12 & 21 \\
\hline Evaluating actions & 3 & 5 & 0 & 8 & 0 & 1 & 7 & 8 \\
\hline Informing actions & 8 & 8 & 0 & 16 & 1 & 2 & 13 & 16 \\
\hline Repeating actions & 3 & 4 & 0 & 7 & 0 & 0 & 8 & 8 \\
\hline Total & 27 & 23 & 0 & 50 & 2 & 13 & 44 & 59 \\
\hline
\end{tabular}


Table 9 Supportive actions across segments in percent

\begin{tabular}{|c|c|c|c|c|c|c|c|c|}
\hline \multirow{2}{*}{$\begin{array}{l}\text { Supportive action type } \\
\text { percent }\end{array}$} & \multicolumn{4}{|l|}{ Year 0} & \multicolumn{4}{|l|}{ Year 3} \\
\hline & $\begin{array}{l}\text { Segment } \\
1\end{array}$ & $\begin{array}{l}\text { Segment } \\
2\end{array}$ & $\begin{array}{l}\text { Segment } \\
3\end{array}$ & Total & $\begin{array}{l}\text { Segment } \\
1\end{array}$ & $\begin{array}{l}\text { Segment } \\
2\end{array}$ & $\begin{array}{l}\text { Segment } \\
3\end{array}$ & Total \\
\hline Directing actions & 15 & 22 & 0 & 18 & 0 & 15 & 9 & 10 \\
\hline promoting actions & 33 & 4 & 0 & 20 & 50 & 62 & 27 & 36 \\
\hline evaluating actions & 11 & 22 & 0 & 16 & 0 & 8 & 16 & 14 \\
\hline informing actions & 30 & 35 & 0 & 32 & 50 & 15 & 30 & 27 \\
\hline Repeating actions & 11 & 17 & 0 & 14 & 0 & 0 & 18 & 14 \\
\hline
\end{tabular}

Table 10 Student contributions across the lesson segments

\begin{tabular}{|c|c|c|c|c|c|c|c|c|}
\hline \multirow[t]{2}{*}{ Student contributions } & \multicolumn{4}{|l|}{ Lesson 1} & \multicolumn{4}{|l|}{ Lesson 2} \\
\hline & Segment 1 & Segment 2 & Segment 3 & Total & Segment 1 & Segment 2 & Segment 3 & Total \\
\hline \multicolumn{9}{|l|}{ Number of instances } \\
\hline $\mathrm{P} / \mathrm{F}$ & 26 & 23 & 0 & 49 & 0 & 11 & 39 & 50 \\
\hline $\mathrm{J}$ & 2 & 1 & 0 & 3 & 0 & 0 & 12 & 12 \\
\hline $\mathrm{G}$ & 0 & 0 & 0 & 0 & 0 & 0 & 0 & 0 \\
\hline \multicolumn{9}{|c|}{ Percent (of categorized instances) } \\
\hline $\mathrm{P} / \mathrm{F}$ & 93 & 96 & 0 & 94 & 0 & 100 & 76 & 81 \\
\hline $\mathrm{J}$ & 7 & 4 & 0 & 6 & 0 & 0 & 24 & 19 \\
\hline $\mathrm{G}$ & 0 & 0 & 0 & 0 & 0 & 0 & 0 & 0 \\
\hline
\end{tabular}

Funding This material is based upon work supported by the National Science Foundation under Grant Nos. (1814114 and 1223074). Any opinions, findings, and conclusions or recommendations expressed in this material are those of the author(s) and do not necessarily reflect the views of the National Science Foundation.

Open Access This article is licensed under a Creative Commons Attribution 4.0 International License, which permits use, sharing, adaptation, distribution and reproduction in any medium or format, as long as you give appropriate credit to the original author(s) and the source, provide a link to the Creative Commons licence, and indicate if changes were made. The images or other third party material in this article are included in the article's Creative Commons licence, unless indicated otherwise in a credit line to the material. If material is not included in the article's Creative Commons licence and your intended use is not permitted by statutory regulation or exceeds the permitted use, you will need to obtain permission directly from the copyright holder. To view a copy of this licence, visit http://creativecommons.org/licenses/by/4.0/.

\section{References}

Anthony, G., Kaur, B., Ohtani, M., \& Clarke, D. (2013). The learner's perspective study: Attending to student voice. In Student voice in mathematics classrooms around the world (pp. 1-11). Brill Sense.

Askew, M. (1997). Effective teachers of numeracy. King's College London.

Australian Curriculum, A.a. R. A. A. (2017). Bildungspläne baden-württemberg.

Baden-Württemberg, M. f. K. J. u. S. (2016). Bildungspläne baden-württemberg. 
Ball, D. (1993). With an eye on the mathematical horizon: Dilemmas of teaching elementary school mathematics. Elementary School Journal, 93(4), 373-397 http://stats.lib.pdx.edu/proxy.php?url=http://search.ebscohost. com/login.aspx?direct=true $\& \mathrm{db}=$ eric $\& \mathrm{AN}=\mathrm{EJ} 461722 \&$ site=ehost-live

Ball, D. L., \& Bass, H. (2003). Making mathematics reasonable in school. A research companion to principles and standards for school mathematics (pg. 27-44). NCTM.

Bikner-Ahsbahs, A., \& Prediger, S. (2006). Diversity of theories in mathematics education - how can we deal with it? Zentralblatt für Didaktik der Mathematik, 38(1), 52-57.

Bikner-Ahsbahs, A., \& Prediger, S. (2010). Networking of theories - an approach for exploiting the diversity of theoretical approaches. In B. Sriraman, \& L. English (Eds.), Theories of mathematics education (pp. 483506). Berlin, Heidelberg: Springer.

Bikner-Ahsbahs, A., \& Prediger, S. (2014). Networking of theories as a research practice in mathematics education. Springer.

Boaler, J., \& Staples, M. (2008). Creating mathematical futures through an equitable teaching approach: The case of railside school. Teachers College Record, 110(3), 608-645.

Brodie, K. (2010). Learning mathematical reasoning in a collaborative whole-class discussion. In K. Brodie (Ed.), Teaching mathematical reasoning in secondary school classrooms (pp. 57-72). Boston: Springer. [Record \#1578 is using a reference type undefined in this output style.]

Brown, R., \& Renshaw, P. (2000). Collective argumentation: A sociocultural approach to reframing classroom teaching and learning. In H., Teoksessa Cowie \& G. van der Aalswoort (Eds.), Social interaction in learning and instruction. The meaning of discourse for the construction of knowledge. Amsterdam: Bergamon Press.

Cai, J., Kaiser, G., Perry, G., \& Wong, N.-Y. (2009). Effective mathematics teaching from teachers' perspectives: National and cross national studies. Rotterdam: Sense Publlishing.

Cengiz, N., Kline, K., \& Grant, T. J. (2011). Extending students' mathematical thinking during whole-group discussions. Journal of Mathematics Teacher Education, 14(5), 355-374.

Chapin, S. H., O’Connor, C., \& Anderson, N. C. (2013). Classroom discussions in math. Math Solutions.

Charalambous, C. Y., \& Hill, H. C. (2012). Teacher knowledge, curriculum materials, and quality of instruction: Unpacking a complex relationship. Journal of Curriculum Studies, 44(4), 443-466.

Charalambous, C. Y., \& Praetorius, A.-K. (2018). Studying mathematics instruction through different lenses: Setting the ground for understanding instructional quality more comprehensively. ZDMMathematics Education, 50(3), 355-366.

Chi, M. T., \& Wylie, R. (2014). The icap framework: Linking cognitive engagement to active learning outcomes. Educational psychologist, 49(4), 219-243.

Cobb, P., \& Yackel, E. (1996). Constructivist, emergent, and sociocultural perspectives in the context of developmental research. Educational psychologist, 31(3-4), 175-190.

Cohen, D. K., Raudenbush, S. W., \& Ball, D. L. (2003). Resources, instruction, and research. Educational evaluation and policy analysis, 25(2), 119-142.

Conner, A., Singletary, L. M., Smith, R. C., Wagner, P. A., \& Francisco, R. T. (2014). Teacher support for collective argumentation: A framework for examining how teachers support students' engagement in mathematical activities. Educational Studies in Mathematics, 86(3), 401-429.

da Ponte, J. P., \& Quaresma, M. (2016). Teachers' professional practice conducting mathematical discussions. Educational Studies in mathematics, 93(1), 51-66.

De Villiers, M. D. (1990). The role and function of proof in mathematics. Pythagoras, 24, 17-24.

Department for Education (2014) The national curriculum in England: Complete framework for key stages 1 to 4. Available at: https://www.gov.uk/government/publications/national-curriculum-in-england-framework-forkey-stages-1-to-4

Driscoll, M. (1999). Fostering algebraic thinking: A guide for teachers, grades 6-10. Heinemann.

Ellis, A. B. (2007). A taxonomy for categorizing generalizations-generalizing actions and reflection generalizations. Journal of the Learning Sciences, 16(2), 221-262. http://stats.lib.pdx.edu/proxy.php?url=http://search. ebscohost.com/login.aspx?direct=true $\& \mathrm{db}=$ eric $\& A N=E J 772330 \&$ site=ehost-live. https://doi.org/10.1080/ 10508400701193705

Fernandez, C., Yoshida, M., \& Stigler, J. W. (1992). Learning mathematics from classroom instruction: On relating lessons to pupils' interpretations. The Journal of the Learning Sciences, 2(4), 333-365.

Franke, M. L., Kazemi, E., \& Battey, D. (2007). Mathematics teaching and classroom practice. Second handbook of research on mathematics teaching and learning, 1(1), 225-256.

Franke, M. L., Webb, N. M., Chan, A. G., Ing, M., Freund, D., \& Battey, D. (2009). Teacher questioning to elicit students' mathematical thinking in elementary school classrooms. Journal of Teacher Education, 60(4), 380-392.

Frey, N., \& Fisher, D. (2010). Identifying instructional moves during guided learning. The Reading Teacher, 64(2), 84-95. 
Hawkins, D. (2002). I, thou, and it. In The informed vision: Essays on learning and human nature (pp. 51-64). New York: Algora Publishing.

Henningsen, M., \& Stein, M. K. (1997). Mathematical tasks and student cognition: Classroom-based factors that support and inhibit high-level mathematical thinking and reasoning. Journal for Research in Mathematics Education, 524-549.

Herbel-Eisenmann, B. A., \& Otten, S. (2011). Mapping mathematics in classroom discourse. Journal for Research in Mathematics Education, 42(5), 451-485.

Hufferd-Ackles, K., Fuson, K. C., \& Sherin, M. G. (2004). Describing levels and components of a math-talk learning community. Journal for research in mathematics education, 81-116.

Jacobs, V., \& Spangler, D. (2017). Research on core practices in k-12 mathematics teaching. In J. Cai (Ed.), Compendium for research in mathematics education (pp. 766-792). National Council of Teachers of Mathematics.

Jaffe, A. (1997). Proof and the evolution of mathematics. Synthese, 111(2), 133-146.

Jeannotte, D., \& Kieran, C. (2017). A conceptual model of mathematical reasoning for school mathematics. Educational Studies in Mathematics, 96(1), 1-16.

Lampert, M. (2001). Teaching problems and the problems of teaching. Yale University.

Lampert, M., Franke, M. L., Kazemi, E., Ghousseini, H., Turrou, A. C., Beasley, H., ... Crowe, K. (2013). Keeping it complex using rehearsals to support novice teacher learning of ambitious teaching. Journal of Teacher Education, 64(3), 226-243.

Leinhardt, G., \& Steele, M. (2005). Seeing the complexity of standing to the side: Instructional dialogues. Cognition and Instruction, 23, 87-163.

Lozano, M.-D. (2017). Investigating task design, classroom culture and mathematics learning: An enactivist approach. ZDM-Mathematics Education, 49(6), 895-907.

Mata-Pereira, J., \& da Ponte, J.-P. (2017). Enhancing students' mathematical reasoning in the classroom: Teacher actions facilitating generalization and justification. Educational Studies in Mathematics, 96(2), 169-186.

Melhuish, K., \& Thanheiser, E. (2017). Using formative evaluation to support teachers in increasing student reasoning. In L. West \& M. Boston (Eds.), Annual perspectives in mathematics education 2017: Reflective and collaborative processes to improve mathematics teaching (pp. 183-200). National Council of Teachers of Mathematics.

Melhuish, K., Thanheiser, E., \& Fagan, J. (2019). The student discourse observation tool: Supporting teachers in noticing justifying and generalizing. Mathematics Teacher Educator, 7(2), 57-74.

Melhuish, K., Thanheiser, E., \& Guyot, L. (2018). Elementary school teachers' noticing of essential mathematical reasoning forms: Justification and generalization. Journal of Mathematics Teacher Education, 1-33.

Munter, C. (2014). Developing visions of high-quality mathematics instruction. Journal for Research in Mathematics Education, 45(5), 584-635.

Nasir, N. i. S., \& Cobb, P. (2006). Improving access to mathematics: Diversity and equity in the classroom. ERIC: Multicultural education series.

National Council of Teachers of Mathematics. (2000). Principles and standards for school mathematics. Reston, VA: National Council of Teachers of Mathematics.

National Council of Teachers of Mathematics. (2018). Catalyzing change in high school mathematics. National Council of Teachers of Mathematics.

National Governors Association Center for Best Practices \& Council of Chief State School Officers. (2010). Common core state standards for mathematics. Washington, DC: Authors.

National Research Council (Ed.). (2001). Adding it up: Helping children learn mathematics. National Academy Press.

Ozgur, Z., Reiten, L., \& Ellis, A. B. (2015). On framing teacher moves for supporting student reasoning. North American Chapter of the International Group for the Psychology of Mathematics Education.

Praetorius, A.-K., \& Charalambous, C. Y. (2018). Classroom observation frameworks for studying instructional quality: Looking back and looking forward. ZDM-Mathematics Education, 50(3), 535-553.

Prediger, S., Bikner-Ahsbahs, A., \& Arzarello, F. (2008). Networking strategies and methods for connecting theoretical approaches: First steps towards a conceptual framework. ZDM-Mathematics Education, 40(2), $165-178$.

Reid, D. A. (2002). Conjectures and refutations in grade 5 mathematics. Journal for research in mathematics education, 5-29.

Remillard, J. (1996). Curriculum materials in mathematics education reform. PME CONFERENCE.

Rezat, S., \& Sträßer, R. (2012). From the didactical triangle to the socio-didactical tetrahedron: Artifacts as fundamental constituents of the didactical situation. ZDM-Mathematics Education, 44(5), 641-651.

Rowland, T., Huckstep, P., \& Thwaites, A. (2005). Elementary teachers' mathematics subject knowledge: The knowledge quartet and the case of naomi. Journal of mathematics teacher education, 8(3), 255-281. 
Sahin, A., \& Kulm, G. (2008). Sixth grade mathematics teachers' intentions and use of probing, guiding, and factual questions. Journal of mathematics teacher education, 11(3), 221-241.

Schoenfeld, A. H. (2011). Toward professional development for teachers grounded in a theory of decision making. ZDM-Mathematics Education, 43(4), 457-469.

Schoenfeld, A. H. (2012). Problematizing the didactic triangle. ZDM-Mathematics Education, 44(5), 587-599.

Schoenfeld, A. H. (2018). Video analyses for research and professional development: The teaching for robust understanding (tru) framework. Zentralblatt fuer Didaktik der Mathematick, 50(3), 491-506.

Sfard, A. (2012). Introduction: Developing mathematical discourse-some insights from communicational research. International Journal of Educational Research, 51-52, 1-9.

Simon, M. A., \& Blume, G. W. (1996). Justification in the mathematics classroom: A study of prospective elementary teachers. The Journal of Mathematical Behavior, 15(1), 3-31.

Sleep, L. (2012). The work of steering instruction toward the mathematical point: A decomposition of teaching practice. American Educational Research Journal, 49(5), 935-970.

Smith, E. (1998). Social constructivism, individual constructivism and the role of computers in mathematics education. The Journal of Mathematical Behavior, 17(4), 411-425.

Smith, M., \& Stein, M. K. (1998). Selecting and creating mathematical tasks: From research to practice. Mathematics Teaching in the Middle School, 3(5), 344-350.

Sowder, L., \& Harel, G. (1998). Types of students' justifications. The Mathematics Teacher, 91(8), 670-675.

Staples, M. (2007). Supporting whole-class collaborative inquiry in a secondary mathematics classroom. Cognition and Instruction, 25(2-3), 161-217.

Staples, M., Bartlo, J., \& Thanheiser, E. (2012). Justification as a teaching and learning practice: Its (potential) multifacted role in middle grades mathematics classrooms. Journal of Mathematical Behavior, 31(4), 447-462. http://stats.lib.pdx.edu/proxy.php?url=http://search.ebscohost.com/login. aspx?direct=true \&db=eric \&AN=EJ983356\&site=ehost-live. https://doi.org/10.1016/j.jmathb.2012. 07.001

Staples, M., \& Newton, J. (2016). Teachers' contextualization of argumentation in the mathematics classroom. Theory into Practice, 55(4), 294-301.

Stein, M. K., Crowley, K., \& Resnick, L. (2016). Education policy and the learning sciences: The case for a new alliance. Reflections on the Learning Sciences, 210-233.

Stein, M. K., Engle, R. A., Smith, M., \& Hughes, E. K. (2008). Orchestrating productive mathematical discussions: Five practices for helping teachers move beyond show and tell. Mathematical thinking and learning, 10(4), 313-340.

Stein, M. K., \& Smith, M. (1998). Mathematical tasks as a framework for reflection: From research to practice. Mathematics teaching in the middle school, 3(4), 268-275.

Stein, M. K., \& Smith, M. (2011). 5 practices for orchestrating productive mathematics discussions. National Council of Teachers of Mathematics.

Stigler, J. W., \& Hiebert, J. (1999). The teaching gap. The Free Press.

Stigler, J. W., \& Perry, M. (1988). Mathematics learning in Japanese, Chinese, and American classrooms. New Directions for Child and Adolescent Development, 1988(41), 27-54.

Stylianides, A. J. (2007). Proof and proving in school mathematics. Journal for Research in Mathematics Education, 38(3), 289-321 http://stats.lib.pdx.edu/proxy.php?url=http://search.ebscohost.com/login.aspx? direct=true \&db=eric\&AN=EJ765496\&site=ehost-live http://my.nctm.org/eresources/article_summary.asp? URI=JRME2007-05-289a\&from=B

Tabach, M., Rasmussen, C., Dreyfus, T., \& Apkarian, N. (2020). Towards an argumentative grammar for networking: A case of coordinating two approaches. Educational Studies in Mathematics, 103(2), 139-155.

Teachers Development Group. (2013). How math teaching matters. Best Practices Notebook.

Turner, E., Dominguez, H., Maldonado, L., \& Empson, S. (2013). English learners' participation in mathematical discussion: Shifting positionings and dynamic identities. Journal for Research in Mathematics Education, 44(1), 199-234.

Walshaw, M., \& Anthony, G. (2008). The teacher's role in classroom discourse: A review of recent research into mathematics classrooms. Review of educational research, 78(3), 516-551.

Williams, S. R. (1993). Mathematics and being in the world: Toward an interpretive framework. For the Learning of Mathematics, 13(2), 2-7.

Wood, T. (1999). Creating a context for argument in mathematics class. Journal for research in mathematics education, 171-191.

Publisher's note Springer Nature remains neutral with regard to jurisdictional claims in published maps and institutional affiliations. 